\title{
LA FAMILIA Y LOS MONSTRUOS DE LA HETERONORMATIVIDAD. LA «FUTURIDAD REPRODUCTIVA» EN LA NARRATIVA FANTÁSTICA DE SAMANTA SCHWEBLIN
}

\author{
Atilio R. Rubino \\ Universidad Nacional de La Plata / CONICET \\ atiliorubino@yahoo.com.ar \\ SiLvina SÁNCHEZ \\ Universidad Nacional de La Plata / CONICET \\ silvina_sanchez80@hotmail.com
}

Recibido: 27-07-2020

Aceptado: 30-08-2021

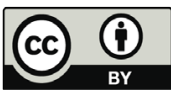

RESUMEN

La narrativa de Samanta Schweblin aborda muy a menudo las relaciones familiares y la maternidad/paternidad. Este artículo analiza, desde una perspectiva sexo-disidente, ese tema en dos relatos de Samanta Schweblin, «Conservas» (2012) y Distancia de rescate (2014). El modo fantástico en ambos textos permite el ingreso en la narrativa de lo otro de la cultura, lo impensable, lo imposible respecto a los órdenes normalizadores de la institución familiar. «Conservas» pone en juego una inversión fantástica del embarazo pero solo como un modo de reproducir los ideales heteronormativos de la familia nuclear burguesa. Distancia de rescate, leída generalmente como una narrativa distópica sobre el monocultivo de soja y el envenenamiento de la tierra, puede pensarse a partir de otra clave de lectura: el deseo no heteronormativo entre las protagonistas como la fuga a los imperativos de la maternidad y el cuidado, que deviene fantástico desde la perspectiva heteropatriarcal.

Palabras clave: Samanta Schweblin; fantástico; maternidad; disidencia sexual; nueva narrativa argentina. 
THE FAMILY AND THE MONSTERS OF HETERONORMATIVITY. THE «REPRODUCTIVE FUTURE» IN SAMANTA SCHWEBLIN'S FANTASTIC FICTION

\section{ABSTRACT}

Samanta Schweblin's narrative very often deals with family relationships and motherhood/paternity. This article analyzes, from a sex-dissident perspective, that theme in two works by Samanta Schweblin: the short story «Conservas» (2012) and the short novel Distancia de rescate (2014). In both texts the fantastic mode allows one to enter into the narrative of 'the other' in culture, the unthinkable, the impossible with respect to the normalizing orders of the family institution. «Conservas» puts into play a fantastic inversion of pregnancy but only as a way of reproducing the heteronormative ideals of the bourgeois nuclear family. Distancia de rescate, usually read as a dystopian narrative about the soybean monoculture and the poisoning of the earth, can be thought of from another key reading: the non-heteronormative desire among the protagonists as an escape from the imperatives of motherhood and care, which becomes fantastic from the heteropatriarchal perspective.

KeYwords: Samanta Schweblin; the fantastic; motherhood; sexual dissidence; new Argentinean narrative.

«Donner la vie, c'est fantastique»

VIRGINIE DESPENTES

\section{Matar Al NiÑo es FAntÁstico}

«Dar la vida es fantástico», dice Virginie Despentes en tono irónico para hablar de los imaginarios de la maternidad como un modo de explotación y dominación:

Tengan hijos, es fantástico, se sentirán más mujer y más cumplidas que nunca», pero ténganlos en una sociedad en hundimiento (...). Sin hijo, no hay felicidad femenina, pero criar nenes en condiciones decentes será casi imposible. De todas formas, es imprescindible que las mujeres sientan que fracasan. Emprendan lo que emprendan, se debe poder demostrar que lo hicieron mal (Despentes, 2007: 20-21). 
En este sentido, formar una familia y tener hijos es la mayor promesa de felicidad (Ahmed, 2019: 97). No solo porque el sistema patriarcal se apropia «del trabajo y la capacidad reproductiva de las mujeres, que son imprescindibles para la continuidad de la vida social» (Rosenberg, 2007: 211), sino también porque, si el patriarcado asocia lo femenino a la maternidad y esta al cuidado y la abnegación, de modo tal que eterniza un tipo de organización que en realidad es contingente; entonces, lo contrario, la no maternidad, en un mundo capitalista patriarcal y heteronormativo, aparece casi como un imposible. El deseo de no ser madre, de no ser padres, de no producir descendencia mediante la reproducción de la institución de la familia heterosexual entra en esa zona de lo innombrable, de lo inexpresable, de lo irrepresentable e ininteligible que, según Rosemary Jackson, es propia del modo fantástico pues este permite «hacer visible lo que no se ve, articular lo que no se dice» (Jackson, 1986: 45).

Para el sistema capitalista en su fase neoliberal y para el orden patriarcal en el que vivimos, no todas las formas de vida son igualmente deseables e inteligibles. Si hay un tipo de organización social que ha sido privilegiado como horizonte de realización y como destino de felicidad es la familia, entendida como nuclear, heteronormativa, compuesta por padre, madre y niños. Según Ahmed, la familia es un «objeto feliz», «aquel hacia el cual se dirigen los buenos sentimientos y que ofrece un horizonte de experiencia compartido» (2019: 96). Ahmed considera que la familia feliz es un objeto porque es «algo que nos afecta, algo hacia lo cual somos direccionados» (2019: 97). Y esto tiene una carga importante de reproducción social, confirmar el proyecto de la familia y actualizar su herencia significa a la vez convalidar un cierto orden de cosas (Ahmed, 2019: 101-102), porque también la felicidad — como institución u objeto social y como dispositivo normalizador- es lo que se obtiene por desear de la manera correcta (Ahmed, 2019: 84). Y acá «correcta» significa también «straight», heterosexual.

Para Ahmed, la felicidad no solo es compulsiva, sino que también es siempre una promesa, se arroja hacia el futuro, «reenvía hacia adelante» y, por eso, implica una postergación (Ahmed, 2019: 86). Desde su propuesta de la negatividad para pensar la teoría queer, Lee Edelman utiliza la figura del «Niño» para dar cuenta de aquello que comparten todos los discursos políticos, la «futuridad reproductiva» (2014: 18). Según este autor, los discursos políticos homolesbotransfóbicos suelen utilizar la figura difusa del cuidado de los niños, pero no tanto de los niños reales, existentes, sino de los niños futuros, imaginarios y fantasmáticos, ideales y puros, lo que encubre la reproducción del orden heteropatriarcal, pues la «futuridad reproductiva» preserva «el privilegio absoluto de la heteronormatividad»(2014: 19), alimentada 
por «las políticas de la esperanza - heteronormativas, reproductivas y de "mirar hacia delante" » (Halberstam, 2018: 117). De este modo, cualquier cosa que rechace el mandato de la futuridad, aparecerá como «una amenaza no sólo para la organización de un orden social dado, sino también, y de forma más ominosa, para el orden social mismo, ya que amenaza la lógica del futurismo» (Edelman, 2014: 30).

En la literatura fantástica - y, particularmente, en muchos cuentos y novelas de Samanta Schweblin — lo indecible de la cultura retorna como monstruoso, como ominoso. De hecho, la narrativa de Samanta Schweblin pone en primer plano las relaciones familiares, las afectividades, los vínculos como modos de promover, habilitar o denegar formas de vida. En muchos de sus textos, esas relaciones se ven desfiguradas y resquebrajadas por un acontecer perturbador, de modo tal que, en el orden de lo cotidiano algo se vuelve extraño, diferente, otro, y amenaza con romper los cimientos de la organización familiar y social.

Si en la literatura argentina del siglo xx las madres han tenido un lugar marginal, siempre objetos y no sujetos de la representación, narradas generalmente desde la voz de los hijos (Domínguez, 2007: 16), sin lograr subvertir el relato hegemónico (Domínguez, 2007: 20), entonces es en la narrativa reciente de las últimas décadas en la que esto comienza a cambiar. Ahora, en muchos casos, son las protagonistas las que ponen en primer plano cómo se vive la maternidad frente a las presiones del imaginario cultural, de los mandatos patriarcales y de los roles sociales prefijados. Las nuevas narrativas de la maternidad se distancian de los esencialismos y de las interpretaciones que ponen el énfasis en lo biológico, para explorar las tensiones entre disposición biológica y dispositivos culturales, entre prácticas y discursos hegemónicos sobre la maternidad y lo que éstos ocultan o silencian.

En este sentido, los textos literarios de las últimas décadas que abordan el tema vuelven a lo que podríamos llamar, en términos de Raymond Williams (2000), tensiones entre ideología y experiencia; en este caso, particularmente, entre los saberes, creencias y valores construidos sobre la maternidad con un efecto normalizador y disciplinario, por un lado, y la experiencia de la maternidad tal como es vivida y sentida, en cuerpo propio y en primera persona, por otro. La experiencia no se correlaciona con los mandatos, más bien se desajusta, mostrando las tensiones, incongruencias y conflictos entre el deber ser y lo que efectivamente somos, entre lo que deberíamos hacer y lo que sucede cuando actuamos y sentimos. En el relato fantástico se explora, justamente, esa otra zona ausente - por indecible - de la cultura y de los relatos hegemónicos, porque se ve como una amenaza al orden familiar y a la heteronormatividad. 
Si entendemos el fantástico como «un discurso en relación intertextual constante con ese otro discurso que es la realidad, entendida siempre como una construcción cultural» (Roas, 2011: 9), atravesada, a su vez, por «esa razón homogeneizadora que organiza nuestra percepción del mundo y de nosotros mismos» (Roas, 2011: 14), son, justamente, las experiencias, sentimientos y deseos contrarios o disímiles al orden social hegemónico los que se vuelven, en los relatos fantásticos de Samanta Schweblin, amenazantes como terroríficos, porque desafían las gramáticas de la cultura.

Nos centraremos, fundamentalmente, en dos relatos en donde el deseo, el placer o el goce intervienen en el discurrir esperable de la maternidad como mandato y en la futuridad de la procreación humana, de modo tal que la experiencia y los regímenes de lo sensible dislocan la reproducción del orden social. Nos interesa pensar el fantástico desde una dimensión sexo-disidente, que implica quizá posicionarnos desde la perspectiva del monstruo, de ese «otro» que resulta amenazante, o desde el otro lado del espejo, en donde las cosas se ven a la inversa, respecto a cómo son o deberían ser, es decir, en esa «oscura zona negativa» de la cultura, la de «lo malo, lo demoníaco, lo bárbaro», expresable, según Jackson, recién con su «reconocimiento en el fantástico moderno como lo "invisible" de la cultura» (1986: 181).

\section{UN PEQUEÑO CAMBIO EN LA ORGANIZACIÓN DE LOS HECHOS}

En general, las representaciones culturales sobre la maternidad se construyen con sentidos que, además de ser certeros y únicos, se vuelven determinantes para la configuración de la identidad. Ante la pregunta de si una mujer es madre, la respuesta solo puede ser una: afirmativa o negativa. Ante la pregunta a una madre sobre si ama a sus hijos, la sociedad no admite la duda. No se toleran ambigüedades, ni contradicciones que agrieten los sentidos unívocos que organizan la vivencia de la maternidad según el orden de la cultura. El cuento «Conservas» de Samanta Schewblin, publicado en Pájaros en la boca (2009), descalabra esta ficción de univocidad y pone en el centro del relato la duda y la incertidumbre de la mujer ante su maternidad. Ante el embarazo reciente, la protagonista se permite dudar, no sabe si quiere o no quiere realmente a Teresita, o quizás sí la quiere, pero no en ese momento en que apareció en su vida. Cuando su madre y su suegra van de visita con regalos para la beba, ella no puede dejar de repetir la frase «no sé»: 
—Ay, no sé... — digo yo, y no sé si me refiero al regalo o a Teresita—. La verdad es que no sé - le digo más tarde a mi suegra cuando cae con un juego de sabanitas de colores—, no sé — digo ya sin saber qué decir, y abrazo las sábanas y me largo a llorar (Schweblin, 2012: 34).

De este modo, aparece la sensación de ambivalencia de la mujer que quiere ser madre pero a la vez tiene otros deseos, otras aspiraciones y otros proyectos. En el desarrollo del embarazo, todo sucede de manera contraria a lo que se espera según las representaciones culturales: la noticia se recibe con tristeza y pura angustia; Manuel, el futuro padre, no parece feliz. El cuerpo de la protagonista comienza a transformarse: «no puedo parar de comer y empiezo a engordar» (Schweblin, 2012: 33), la panza está cada vez más hinchada, sufre insomnio y pasa las noches despierta en su cama. Su pareja se vuelve distante, cumple con las atenciones que ella necesita, le alcanza la comida a la cama o al sillón, limpia la casa, abastece la alacena, pero algo se ha quebrado en el vínculo entre ellos dos: llega tarde del trabajo, se sienta a ver televisión con gesto preocupado, ya casi no le habla. La experiencia se ve confrontada con los guiones de felicidad heteronormativos. Todo lo que se debería sentir y el modo en el que se debería vivir se ven alterados solo por «un pequeño cambio en la organización de los hechos»: ocurre antes de lo previsto. En esa confrontación entre dos mundos - por un lado, el ideal, el organizado, el planificado y, por otro, lo que efectivamente se vive- - se cuela la lógica del modo fantástico:

No puedo entender cómo en un mundo en el que ocurren cosas que todavía me parecen maravillosas, como alquilar un coche en un país y devolverlo en otro, descongelar del freezer un pescado fresco que murió hace treinta días, o pagar las cuentas sin moverse de casa, no pueda solucionarse un asunto tan trivial como un pequeño cambio en la organización de los hechos. Es que simplemente no me resigno (Schweblin, 2012: 26).

Se trata, fundamentalmente, de un problema del tiempo, porque la protagonista no niega el deseo de ser madre, sino que cree que esta situación se ha adelantado en su vida, ha llegado demasiado pronto, cuando no estaba en los planes, cuando aún quedaban muchas otras cosas por hacer: «Me cuesta hacerme a la idea de recibir a Teresita tan temprano, pero tampoco quiero lastimarla» (Schweblin, 2012: 35). Desde el comienzo se construye una relación afectiva con el feto, ya que la protagonista muestra una insistente preocupación por no hacerle daño, pero, sobre todo, porque ya tiene un nombre: Teresita, en femenino y diminutivo. Los guiones heteronormativos de la feli- 
cidad futurizan la vida en la figura del niño al que hay que cuidar, incluso en la forma fantasmática de un imaginario a futuro. Teresita no existe todavía, pero ya tiene un nombre y, con él, una identidad de género asignada compulsivamente. Y el diminutivo con el que se la nombra, a su vez, pone en evidencia los imaginarios de una niñez idealizada. Teresita encarna el «futurismo reproductivo» del que habla Edelman en todo su esplendor. El mundo heteronormativo gira en torno a esa niña que hay que proteger, pero que no es más que una promesa de futuro.

Como no se resignan a su pronta llegada, van a consultar al Doctor Weisman, que le facilita un extraño - y nunca explicitado del todo- método para revertir el embarazo y conservar el feto en un frasco hasta el momento en que se quiera dar curso a su alumbramiento. El tratamiento incluye cambios en la alimentación y en el sueño, unos medicamentos y una serie de ejercicios de respiración, descubiertos y enseñados por el mismo Weisman. La respiración consciente es parte fundamental del método, es un trabajo de auto conocimiento del cuerpo, cuyo objetivo es sentir la dirección en que las energías circulan para lograr darle un cauce inverso al que tienen (Schweblin, 2012: 38).

Pero el tratamiento no solo consiste en eso, sino que, en una primera etapa, los protagonistas deben registrar cada una de las situaciones que fueron viviendo desde que se enteraron del embarazo, apuntando el día y la hora precisos en que cada evento tuvo lugar. Es decir, el procedimiento implica un ejercicio de memoria, puntilloso y detallista, porque luego van a volver a vivir, en una especie de puesta en escena deliberada de antemano, cada una de esas situaciones, tal como sucedieron. Para esto, no basta con la determinación de la pareja, necesitan de la ayuda de sus dos familias, que son informadas de los planes y de los pasos a seguir, sin dejar que opinen del asunto: «Tienen que hacer lo que les decimos (...) en la hora y al tiempo que corresponda» (Schweblin, 2012: 37).

De este modo, el tratamiento consiste en una inversión del curso de los acontecimientos, en una reversión de las temporalidades. Si Teresita se adelantó, y llegó «antes», «tan temprano»; la solución consiste en volver el tiempo atrás y preservar el embrión para el momento indicado. La organización de las temporalidades, ya sea hacia adelante o hacia atrás, obedece a una construcción cronológica y lineal, con una fuerte lógica causal. En este sentido, la temporalidad se simplifica a una única línea de causas y efectos, se puede cronometrar — «hasta dentro de un mes y medio», «el segundo es, quizás, el mes de más cambios», «empieza el tercer mes», «los días del último mes» (Schweblin, 2012: 38, 39, 39, 40)—y se puede rememorar y reconstruir 
con fidelidad. El dispositivo de inversión es la operación fantástica central del cuento y se configura, de manera duplicada, en dos dimensiones fundamentales: se realizan los ejercicios de respiración, que consisten en alternar la dirección de la circulación de la energía, como una especie de reversión del funcionamiento corporal, y, simultáneamente, se recorre para atrás el tiempo de la comedia familiar de la maternidad. Se ha llamado la atención sobre el hecho de que la narradora acuda a las terapias alternativas ya que Weisman, el supuesto doctor, no utiliza los procedimientos tradicionales. Las lecturas de la crítica han señalado este hecho como una actitud subversiva, en la que el deseo de maternidad prima sobre el imperativo biológico y social. Tanto Trejo Valencia (2018) como Astorino, Saporosi y Zicavo (2017) leen el cuento como una representación del aborto en la literatura argentina. Para estos últimos, «el relato tematiza la cuestión de la maternidad como decisión y deseo, y en tanto expresión de autonomía corporal» (Astorino, Saporosi \& Zicavo, 2017: 51), ya que

presenta al embarazo como una cuestión contingente (en la que tiene que mediar una decisión por parte de la mujer) y no como un mandato inexorable de maternidad (ya que puede ser interrumpido). Emerge la idea de «embarazo no deseado» o al menos «no esperado», porque el deseo y la voluntad son contemplados. Allí hay un cuerpo individual, deseante, sexuado. Y por lo tanto, una manifestación de la autonomía corporal de la mujer (Astorino, Saporosi \& Zicavo, 2017: 52).

Sin embargo, hay una invasión médica sobre los cuerpos, una intervención obsesiva que determina todos los hábitos, y, a la vez, el dominio se extiende a las prácticas culturales y a relaciones sociales. La lista de instrucciones no deja resquicio fuera de control, los papeles están asignados y las actuaciones ya dispuestas. Manuel tiene que ser fiel a lo que apuntaron, por eso debe mantenerse alejado de su esposa aproximadamente un mes y medio, aunque ya tenga ganas de acercarse y abrazarla, debe hablar solo lo necesario y volver tarde a la casa algunas noches. Y los padres también cumplen con sus tareas: la madre de Manuel, gradualmente, va realizando menos llamados telefónicos y baja la ansiedad de hablar tanto de Teresita; también los padres de la protagonista van por sus regalos: la toalla con capucha, los escarpines, el cambiador. Además, la madre acaricia la panza por última vez, mientras le dice palabras cariñosas a Teresita: «y dice, ésta es mi Teresita, cómo voy a extrañar a mi Teresita, y yo no digo nada, pero sé que, si hubiera podido, si no hubiera tenido que limitarse a su lista, habría llorado» (Schweblin, 2012: 40). 
Tener todo bajo control y dominar la organización del tiempo funciona como inversión de lo que suscitó el problema existencial de la protagonista: la falta de previsión, la llegada del embarazo fuera de sus planes. Se pone en escena la teatralización de la maternidad: vuelven a acontecer, pero esta vez bajo un guion estricto, los gestos de afecto, los obsequios, los llamados; la madre como objeto de todas las atenciones y cuidados, el espectáculo de la dulce espera. Mediante la inversión fantástica del proceso del embarazo y la procreación se des-ocultan las dimensiones sociales asociadas a la maternidad heteronormativa. En este sentido, el cuento descalabra el imaginario social hegemónico sobre la maternidad que suele reducirla a una relación puramente natural y biológica (Rosenberg, 2007). Muestra que la reversión de lo acontecido no puede reducirse a la dimensión biológica, sino que incluye, con igual atención e importancia, los dispositivos culturales de reproducción social. El tratamiento consiste tanto en invertir el proceso biológico de la gestación como en des-andar las representaciones, imágenes, acciones y gestos que componen el orden simbólico sobre lo materno y lo familiar. Entonces, el texto exhibe esa trama donde biología y cultura no pueden escindirse ni concebirse como dimensiones separadas. Y repone el carácter contingente, cultural y social de la maternidad.

Pero si, como afirma Trejo Valencia, en «Conservas» opera una «perturbadora metáfora» que «entiende que "dar vida" es al mismo tiempo perder su propia existencia» (2018: 87), es importante tener en cuenta que este proceso fantástico de inversión de la gestación también cuestiona la idea de la maternidad deseada. Como dice De Leone:

se opta por el manejo de los propios riesgos, mediante los cuales los individuos se convierten en gestores de sí mismos, sujetos que planifican sus vidas del mismo modo en que un empresario delinea las estrategias de sus negocios, evaluando riesgos, costos y beneficios y haciendo inversiones convenientes (2018: 40).

El proceso inverso, lejos de poner en práctica un «deseo», lo que hace es futurizar el imperativo de la maternidad. Si, al inicio, el relato postula una contradicción entre los proyectos personales y los de familia, el modo fantástico de la inversión de la gestación permite la complementación de ambos guiones: desarrollar una vida profesional y también una familia, ambas igualmente exitosas. «No podemos arriesgarnos a salirnos ni un segundo del guion» (Schweblin, 2012: 38), dice la narradora. El cuento pone en evidencia la imposibilidad de salirse de los guiones de felicidad asociados a la familia 
heteronormativa y al futurismo reproductivo. El proceso de inversión se lleva adelante mediante la «lógica de la empresa» como un «operador fundamental en la construcción biopolítica de los cuerpos y las formas de vida» (De Leone, 2018: 40). Se trata del funcionamiento de lo que Deleuze (1991) llamó las sociedades de control. Para ingresar en la vida (la vida cualitativa, la vida que vale como vida, que cuenta como vida), es necesario seguir los guiones del éxito mediante la lógica del ascenso empresarial. No se trata de dar o quitar la vida, sino, justamente, del ingreso en —o el acceso a- ella.

De esta forma, podemos ver hasta qué punto la lógica de la empresa propia de las sociedades de control (Deleuze, 1991) controla y delinea las vidas vivibles, el acceso a la vida en su dimensión social. Aunque se trate del «asesoramiento de un seudo especialista que actúa con lógicas alternativas a las del saber científico-farmacológico, en el marco de circuitos no institucionales» (De Leone, 2018: 42), constituye un poder horizontal que instaura las vidas vivibles y las que no, las vidas a futurizar en tanto familia nuclear. Si en las sociedades de control la lógica de la empresa se impone en todos los órdenes de la vida, también lo hace en el orden familiar. Si la necesidad de postergar a Teresita, de postergar la procreación y la consumación de la familia tradicional, obedece a las oposiciones embarazo, familia y proyectos personales, la resolución fantástica las reorganiza para cumplir con ambos imperativos de forma ordenada y exitosa. Teresita se arroja como imaginario fantasmático y como deseo hacia un futuro, pero no se anula. Y es que el niño como imaginario, diría Edelman, es pura futuridad, es la vida en términos sociales -y no meramente biológicos_- El deseo entonces permite ser cuestionado y podríamos preguntarnos en este cuento hasta dónde somos dueños del deseo o, más bien, objetos de un deseo deseado para nosotros por la sociedad. Pero ahí, como suele sugerir Leonor Silvestri (2017: 179), el concepto de deseo es una trampa. La futuridad que implica la idea del deseo (a diferencia del presente del goce) nos convierte más bien en objetos del mismo, deseamos porque hemos sido deseados, deseamos lo que han delineado para nosotros, para nuestras vidas.

Con el transcurso de los meses el cuerpo empieza a cambiar nuevamente: la panza disminuye, se siente menos ansiosa y deprimida, duerme mejor a la noche. Hasta que llegan al tiempo cero, el momento del origen, cuando tendrá lugar la expulsión del embrión, que se narra con muchas de las imágenes de una típica escena de parto. Tienen marcada la fecha en el almanaque de la heladera, tal como se hace con la fecha de parto, aunque a la vez tienen cierta incertidumbre sobre cuál será el momento preciso. El varón está 
intranquilo, ansioso, camina por la casa de un lado a otro, mientras la joven aguarda en la cama esperando que comience el trabajo de expulsión. Cuando empieza a tener síntomas, como náuseas, mareos, el estómago que arde y late cada vez más fuerte como si fuera a explotar, surge la necesidad imperiosa de llamar al doctor, igual que en el momento previo del trabajo de parto. Aquí, además, reaparece el miedo, el amor hacia Teresita y el deseo de no lastimarla, de preservarla intacta para más adelante. En definitiva, el deseo de futurizar la maternidad/paternidad, la consolidación de la pareja nuclear heteronormativa. También se observa el desajuste entre las explicaciones y ejercicios que se hicieron previamente y la posibilidad de puesta en acto, tal como podría pensarse entre lo ensayado en el curso de pre-parto y el momento efectivo del mismo: «Pienso en la respiración consciente pero mi cabeza ya está en otra cosa. Tengo miedo. (...) no puedo hablar. Me tiembla el cuerpo, no tengo control sobre él» (Schweblin, 2012: 42-43). Manuel ocupa el rol de acompañante también según las representaciones culturales más difundidas: se arrodilla junto a ella, la toma de la mano, le habla, y cuando la situación avanza se desconcierta: «me mira, no sabe qué hacer» (Schweblin, 2012: 43). Porque la protagonista comienza a sentir muchas ganas de vomitar, arcadas cada vez más violentas que la dejan sin aire, hasta que algo se le atora en la garganta:

Entonces siento algo pequeño, del tamaño de una almendra. Lo acomodo sobre la lengua, es frágil. Sé lo que tengo que hacer pero no puedo hacerlo. Es una sensación inconfundible que guardaré hasta dentro de algunos años. Miro a Manuel, que parece aceptar el tiempo que necesito. Ella nos esperará, pienso. Ella estará bien: hasta el momento indicado. Entonces Manuel me acerca el vaso de conservación, y al fin, suavemente, la escupo (Schweblin, 2012: 43).

Aquí también se construyen algunas inversiones: el feto sale por la garganta en lugar de ser expulsado por la vagina, la bebé se ha convertido en un embrión del tamaño de una almendra, y en lugar de morir, Teresita vuelve a nacer, porque adquiere la posibilidad de estar bien, detenida en el tiempo, vegetando en un frasco de conservas, hasta el momento indicado en que podrá continuar su curso de crecimiento. Es, ahora sí, pura futuridad, la heteronormatividad preñada de futuridad. Pues la familia que puede organizar su vida y planificar el curso de los acontecimientos es la familia burguesa, la que puede acceder económicamente al tratamiento, la que puede disponer del tiempo para realizarlo, porque es necesario que las urgencias materiales y económicas estén aseguradas (Loria Araujo, 2017: 257). Y en la que cada integrante de la familia, madre, padre, abuelos, puede cumplir su rol con éxito, 
pueden seguir los guiones de la felicidad (Ahmed, 2019). En este sentido, se puede desplegar otra dimensión del título: se conserva no solo el embrión en el envase plástico, sino que, a la vez, se conservan las buenas costumbres de la familia nuclear heteronormativa, todos van a desarrollar la comedia de los roles asignados - madre, padre, abuelos, incluso la pequeña Teresita—, pero no ahora sino en el momento oportuno. No cambian las relaciones sociales, el mandato de la maternidad, los comportamientos deseables según el orden simbólico de la cultura, sino que se conservan intactos, en estado latente, se siguen reproduciendo, para ser actualizados cuando sea necesario. En Argentina suele usarse la palabra «conservas» para referirse de forma peyorativa a una ideología conservadora. Y, de hecho, esta es otra de las claves de lectura que el título del cuento nos arroja. Para Edelman, las políticas, del signo que sean, suelen ser «conservadoras», porque, según él, en su centro siempre están «operando para afirmar una estructura, para autentificar un orden social que intenta después trasmitir al futuro en la forma de su Niño interior» (Edelman, 2014: 19). Ese es el sentido que podemos leer también en el cuento de Schweblin, lo que está en juego no es solo el deseo de la maternidad y sus relaciones con la vida en tanto temporalidades, sino, además, la reproducción del orden normal heterosexual — que podemos adjetivar también como «conserva».

En una entrevista Schweblin cuenta una anécdota infantil que luego vincula con este cuento. A los siete años ella tenía un noviecito, en esa especie de juego de niños a la familia que no es más que un dispositivo educacional de la heteronorma:

Un día en que estábamos en su cuarto jugando al Out Run dijo que tenía que decirme algo, y como lo dijo muy serio dejé el joystick a un lado e intenté prestar atención. Dijo que quería que tuviéramos un hijo. Que había estado averiguando cómo se hacía y que quería que yo hiciera también mi parte. Abrió su puño, que hasta entonces tuvo cerrado entre los dos. Tenía en la palma una semilla de naranja y dijo que, si yo tragaba esa «semilla de padre», la semilla crecería en mi «estómago de madre» y un tiempo después nacería el bebé. Empecé a escribir «Conservas» veintitrés años después. Supe el final desde la primera línea, pero en ningún momento pensé que estas historias podrían estar relacionadas. Me había olvidado del asunto de Sergio y su semilla de naranja, y fue sólo durante el proceso de escritura, llegando ya hacia el final de la historia, que recordé la anécdota y supe con precisión desde qué lugar tan lejano venían los miedos, las angustias y los monstruos que una supuesta maternidad a los siete años habían disparado en mi cabeza (Paris, 2014). 
La anécdota infantil de la autora pone de manifiesto hasta qué punto hay cierto orden de la vida que es el único posible, pensable, inteligible, a menos que el modo fantástico lo confronte con lo oculto/ ado de la cultura. La niñez está ya preñada de heteronorma, de reproducción del orden socio-sexual, de futuridad. Pero el niño, como dice Edelman, es siempre fantasmático e ideal, es la anulación del goce presente. Los niños reales no siempre saturan los deseos que les son impuestos como esperanza de la heteronorma arrojada hacia el futuro y, por eso, muchas veces, se convierten en monstruos si, de alguna u otra forma, significan el aborto de la reproducción heterosexual obligatoria. La personificación del feto con el nombre de Teresita, esa almendra que se escupe al final del cuento, investida ya con un nombre y una identidad de género y expresada en un diminutivo que arroja hacia el futuro un afecto no presente sino planificado, es ya, por tanto, pura futuridad, ya es la niña (heterosexual y cisgénero) que será luego y que cargará con el imperativo de seguir reproduciendo el orden social, mediante la institución de la familia.

\section{LA BIKINI DORADA DE CARlA}

La narrativa de Schweblin vuelve muchas veces sobre los monstruos, pero éstos ya no son lo externo, lo que amenaza con romper el orden de lo propio, sino, como lo ominoso freudiano (Das Umheimliche), parten de lo más cotidiano y, muchas veces, podríamos decir, del propio deseo. Distancia de rescate (2015) retoma en el siglo XXI el relato clásico de terror, muy en la línea del género fantástico clásico tal como lo define Todorov (2011). La narración es bastante compleja y alterna dos tipografías, que corresponden a dos voces narrativas, pero que dialogan entre sí. Una es claramente la voz de Amanda, la protagonista, quien junto a su marido y a su hija Nina viaja de vacaciones al campo en la provincia de Buenos Aires. Allí conoce a Carla, una vecina, y a su hijo David. La otra voz narrativa podría ser la de David, pero en esto el texto se vuelve confuso y ambiguo — vacilación típica del fantástico, según Todorov (2011: 24)—. Hacia el final del relato sabemos que Amanda está narrando desde la sala de emergencias del Hospital en la que agoniza por una intoxicación producto de los agroquímicos que se vierten en los campos para mejorar los cultivos. Y la otra voz es la de David, el niño que, sentado junto a su cama, le habla al oído. Sin embargo, el estado de Amanda y el uso de dos tipografías en vez de rayas de diálogo nos hace dudar. Y es que David en la novela es un chico monstruoso: 
—Era mío. Ahora ya no.

La miro sin entender.

-Ya no me pertenece.

- Carla, un hijo es para toda la vida.

-No, querida - dice. Tiene las uñas largas y me señala a la altura de los ojos (Schweblin, 2014: 15).

Intoxicado, como Amanda y como Nina, su madre Carla lo llevó a una bruja para que mediante una transmigración de almas salvara su cuerpo. Claro que esto es lo que Amanda recuerda que le contó Carla, y lo narra interrogada por David mientras agoniza en el hospital. Según este relato, el alma de David - o parte de ella - ya no está en su cuerpo. Después de eso, David actúa de forma extraña y genera miedo en sus padres, ya no es su hijo, es un desconocido, un monstruo. Acá se abren otras posibles interpretaciones: que el diálogo entre Amanda y David sea interno, que sea producto de que parte del alma de David está ahora en Amanda, o quizá que es parte de las alucinaciones de Amanda por la intoxicación. La de David es una voz adulta, que parece guiar a Amanda en los recuerdos y la rememoración. La narración así es siempre en flashback guiada por David para buscar «el punto exacto en el que nacen los gusanos», es decir el momento de la intoxicación de Nina, de su hija, y luego el momento en el que el hilo invisible que une a madre e hija se tensa tanto hasta cortarse. Esa es la «distancia de rescate» anunciada desde el título, el hilo invisible que une a Nina y Amanda, así como antes lo hizo con Amanda y su madre, y que permite rescatar a un hijo de cualquier peligro, la distancia máxima en la que el hijo puede estar seguro. Y ese es justamente el momento en el nacen los gusanos, es decir, en el que adviene la muerte, cuando el hilo se corta o, en realidad, cuando falla y Amanda no puede salvar a Nina de la intoxicación. Es el momento del fracaso materno. Amanda falla en su rol femenino, no puede llevar a cabo su supuesta esencia maternal (Reyes Cortés, 2018). El hilo entre el deber ser y la experiencia también se tensa hasta cortarse.

La crítica se ha ocupado casi exclusivamente del aspecto fantástico asociado con el uso de agrotóxicos en la siembra de monocultivo, por un lado, y de la tematización de la maternidad, por otro. Para Ortega Caicedo, «Si proteger, cuidar, amar, son funciones claves del orden materno, el diálogo novelado busca descubrir el "punto exacto" en donde el hilo invisible que une a la madre con su hija se tensa y amenaza con romperse» (2017: 170). Pero para ella la ruptura de ese hilo invisible no estalla «por descuido materno, sino porque estar en el mundo, su sola habitabilidad, se vuelve una experiencia peligrosa», porque la toxicidad de los campos vuelve al mundo un lugar altamente peli- 
groso, envenenado y «en este escenario de vulnerabilidad extrema, el saber acerca de la distancia de rescate, transmitido de generación en generación, de madre a hija, pierde sustento y valor referencial» (Ortega Caicedo, 2017: 170). En el mismo sentido lo analiza Forttes, quien lee la novela «como una historia de horror en la cual el elemento que más intranquiliza es la incapacidad de la madre de proteger la vida nueva ante la omnipresencia de la industria agro-tóxica en el campo argentino». Para Forttes lo que rompe la distancia de rescate, el vínculo entre madre e hija, es el monocultivo, los agroquímicos, las semillas transgénicas, los herbicidas, y a la vez esto «alegoriza la incapacidad de la madre-naturaleza de alimentar y transmitir los saberes ancestrales que protegen a cada especie» (2018: 147).

Pero lo que resulta llamativo es que la mayoría de las interpretaciones críticas omiten algunos detalles que se vuelven evidentes si pensamos el texto no desde una mirada única — el monocultivo, la industria de los agrotóxicos, la destrucción de la naturaleza, la enfermedad y la muerte como consecuencias inevitables de estos fenómenos- sino desde una lectura fuera de foco, que se atreve a las perspectivas múltiples. Esos detalles mínimos se van entrelazando para componer los modos de la relación entre las dos mujeres adultas, Amanda, la narradora, y Carla:

Carla no hace ningún ruido pero logra hacer que me levante y camine hacia ella. Me gustó desde el principio, desde el día en que la vi cargando los dos baldes de plástico bajo el sol, con su gran rodete pelirrojo y su jardinero de jean. No había visto a nadie usar uno de esos desde mi adolescencia y fui yo quien insistió con las limonadas, y la invitó a tomar mate a la mañana siguiente, y a la siguiente, y a la siguiente también ${ }^{1}$ (Schweblin, 2014: 14).

Desde el principio del relato sabemos que Amanda se siente atraída por Carla: «Me desconcierta que una mujer diez años más grande que yo sea tanto más hermosa» (Schweblin, 2014: 15). El deseo sexual que siente Amanda por Carla queda claro cuando revisamos estos detalles. Un elemento que se vuelve clave por estar cargado de una mirada erotizada es la bikini dorada de Carla y los breteles que se le caen: «Dónde están sus breteles dorados, pienso. Carla es linda. Tu mamá, es muy linda, y hay algo en el recuerdo de esos breteles que me enternece. Me arrepiento tanto de haberle gritado» (2014: 69). Y en la narración de Amanda parecería que ese deseo es mutuo o, al menos, hay también una seducción por parte de Carla: «Tu madre tiene una bikini dorada

1 En este caso la cursiva es nuestra. 
y cuando se mueve en el asiento el perfume de su protector solar se mueve en el coche. Ahora me doy cuenta, ella hace el gesto adrede, es ella la que deja caer el bretel» (2014: 78). De hecho, cuando Amanda decide irse y no volver nunca más de vacaciones al campo, no imagina dejar de disfrutar de la presencia de Carla:

Imagino que dentro de unos minutos me alejaré de la casa alquilada y de la casa de Carla, dejaré el pueblo y año tras año elegiré otro tipo de vacaciones, vacaciones en el mar y muy lejos de este recuerdo. Y ella vendría conmigo, eso creo, que Carla vendría si yo se lo propusiera, sin más que sus carpetas y lo que lleva puesto. Cerca de mi casa compraríamos otra bikini dorada, me pregunto si esas son las cosas que más extrañaría (Schweblin, 2014: 84).

Pero la voz de David la desvía todo el tiempo de esos recuerdos, insistiendo en que eso no es lo importante: Carla, su bikini dorada, su protector y su seducción no son lo importante, lo importante es el fracaso materno, reconocer el punto exacto en el que la distancia de rescate no funciona y nacen los gusanos, cuando se entra en contacto con la muerte. Ahora bien, es este deseo sexual disidente de Amanda quizás el detonante de la falla de la distancia de rescate, de la unión entre madre e hijo, es quizás Amanda una especie de Medea, cuyo deseo lésbico la lleva a descuidar a su hija:

Carla sale de la casa, al fin.

Carla no importa.

Pero camino hacia ella, creo que todavía intento disuadirla del paseo.

No dejes sola a Nina. Ya está pasando.

Carla se acerca con su bolso, sonriente.

No te distraigas.

No puedo elegir qué sigue, David, no puedo volverme hacia Nina.

Está pasando.

¿Qué cosa, David? Dios mío, ¿qué es lo que está pasando?

Los gusanos (Schweblin, 2014: 65).

Cuando van a hacer un picnic al campo y Nina entra en contacto con el veneno, Amanda está ocupada con Carla: «-Mami — dice Nina—, mami - pero no le hago caso, estoy concentrada en Carla y Nina vuelve a alejarse» (2014: 72). Lo que permite que fluya ese deseo disidente, casi incomunicable, es la situación en la que se encuentran solas sin sus maridos. Ambas están casadas, pero sus maridos significan la ausencia. Como ocurre con la relación homosexual en El beso de la mujer araña de Manuel Puig, posibilitada 
por el hecho de estar compartiendo celda en la cárcel, aquí lo que permite que ese deseo lésbico fluya, o se vuelva hasta cierto punto aprehensible, es la ausencia (censuradora, observadora) de los patriarcas. Se trata de una situación que podemos pensar como utópica, desde el punto de vista sexo-disidente. Pero que, más bien, sería acaso distópica, desde la perspectiva del futurismo reproductivo de la heteronormatividad. Porque es esa posibilidad, justamente, la que la lleva a descuidar a su hija: «Me gusta este momento. Estamos bien, tranquilas las tres. Después de esto todo empieza a andar mal» (2014: 69). El goce es una hybris, el disfrute de la presencia de Carla, pero también de estar las tres, como si formaran una familia, Amanda, Nina y Carla, ya que esta última sugiere incluso en un momento - y siempre dentro del relato de Amanda- cierto cariño hacia Nina y la posibilidad tener una nena así (2014: 83). Pero, de todas formas, sería siempre un imposible, algo ininteligible.

Quien enfatiza la lectura de este deseo lésbico en una interpretación que va en la misma línea de la que proponemos aquí es Elsa Drucaroff. Para ella, «Amanda ama a su hija pero también desea — casi imperceptiblemente- a otra mujer. Su mirada/voz narra a Carla con un erotismo intenso, velado y sutil» (Drucaroff, 2018). Eso es lo que la convierte en Medea. No por asesinar a su hija, sino por encontrar su propio deseo personal, solitario, por fuera de la maternidad abnegada que da sentido por completo a la vida de la mujer. En la vida de Amanda ahora hay otro sentido, su deseo hacia Carla, y esto en el relato fantástico tiene consecuencias, porque es un pecado que debe ser castigado:

Distancia de rescate asusta. Nos asusta que ni Carla ni Amanda puedan cuidar a sus hijos porque como todo amor, el de madre también está cargado recónditamente de ambivalencia y en algún lugar de ellas y nosotras, nosotros, madres y padres, subyacen el odio y el impulso filicida. Pero asusta sobre todo lo materno porque desde allí está contado el relato. Y en el mismo momento en que se es madre no sólo se tiene el poder de cuidar vida sino de descuidarla. Algo puede irrumpir siempre para evidenciar la realidad insoslayable y terrorífica de que son una otredad, la diferencia que hemos engendrado en las entrañas que siempre podrá decirnos «yo soy otro» (Drucaroff, 2018).

Se trata del fracaso materno: Amanda no logra ser «buena madre». Los gusanos remiten a una corporalidad abyecta, desde la cual ahora sí es posible narrar el deseo lésbico, desde la enfermedad y la muerte. En el final de la novela, Amanda puede ver más allá, ya no se trata de sus recuerdos, sino de la vida de su marido y su hija (salvada de la intoxicación por haber sido llevada 
por Carla a la casa verde para transmigrar parte de su alma) sin ella. La escena ahora es con los dos maridos y los dos hijos. El marido de Amanda quiere irse, pero en su auto está sentado David, en el lugar en el que suele viajar Nina, y le pide que se baje, a pesar de que se abrocha el cinturón de seguridad y se abraza a su topo de peluche, tal como lo hacía Nina. Pero entre padre e hija no hay conexión especial, no hay distancia de rescate y él no logra reconocer que en David está parte del alma salvada de Nina. Según Forttes: «Una madre habría reconocido la presencia de su hija» (2018: 160). Sin embargo, en la línea de lo trabajado hasta acá, nos interesa distanciarnos de una lectura que pueda esencializar la maternidad. No hay una conexión natural, biológica, entre madre e hijo, sino, más bien, una construcción histórica de la cultura patriarcal. Si el padre no reconoce el alma de Nina a partir de sus gestos cotidianos es porque el cuidado de los niños es el trabajo naturalizado de las madres, romantizados como instinto materno, pero que no deja de ser la apropiación por parte del sistema patriarcal de la fuerza de trabajo de la mujer.

Ahora bien, es importante tener en cuenta que Carla desde el nacimiento de David tenía el temor de que su hijo no fuera normal, que no fuera lo que ella esperaba. «Cuando David nació era un sol» (Schweblin, 2014: 15), le dice a Amanda, pero agrega:

la primera vez que me lo dieron para sostenerlo me angustié muchísimo. Estaba convencida de que le faltaba un dedo (...). La enfermera dijo que a veces pasa con la anestesia, que uno se persigue un poco, y hasta que no conté dos veces los diez dedos de las manos no me convencí de que todo había salido bien. Que no daría ahora porque a David simplemente le faltara un dedo (Schweblin, 2014: 16).

Muchos de los cuentos de Schweblin ponen en escena este miedo asociado a la monstruosidad de los hijos. Así, en «Mariposas», el padre —desde cuya perspectiva se narra - mata a una mariposa mientras espera a la salida del jardín para luego darse cuenta, o sospechar, de que podría ser su recién transformado hijo. En «Pájaros en la boca» es el padre el que narra el horror que siente ante su hija, porque comenzó a comer pajaritos, de lo que culpa a su madre. Es quizás «En la estepa» el más interesante al respecto, porque en él un matrimonio, ante la imposibilidad de procrear, se instala en el campo para salir a la caza de un «eso» (algo así como un animal, pero al que se describe a partir de los imaginarios de la maternidad), hasta que conocen a otro matrimonio que ya tiene el suyo, pero este los ataca violentamente. Eso que tanto se desea no es, en realidad, lo que se esperaba, no condice con el imaginario y, 
por eso, se vuelve monstruoso. En este sentido, también se puede pensar que en Distancia de rescate el niño, David, aunque resulta un monstruo amenazante, es la víctima (González Dinamarca, 2015: 103) de un sistema que futuriza a la figura del niño fantasmal, ideal, imaginado, para desproteger al niño real y sostener una apariencia de normalidad. Desde esta perspectiva, el horror que Distancia de rescate pone en juego en el modo fantástico no es tanto el miedo a la pérdida de la vida del hijo, a no poder evitar que le pase algo, sino, más bien, el miedo a que ese hijo sea un monstruo, que escape a las gramáticas de la normalidad que venimos pensando desde la idea de futuridad reproductiva, el terror ante la posibilidad de que ese hijo no reproduzca el orden heteropatriarcal o sea, quizás, una mariposa queer.

\section{A MOdo DE CONCLUSIÓN: LA INTERRUPCiÓN DE LO REAL}

"¿Qué significaría no estar "luchando por los niños"?», se pregunta Edelman (2014: 19). Esa retórica de la política que usa de excusa el cuidado de los niños para la desprotección, la invisibilización y el «dejar morir» de las personas, esa contradicción es la que abriría en la perspectiva polémica de Edelman una dimensión positiva, de apuesta por el presente, por el goce, por una política queer.

En Distancia de rescate el deseo lésbico opera como una interrupción (o quizás, una «interruqción», en el sentido que propone valeria flores) ${ }^{2}$ de la maternidad, de la repetición de lo mismo de la heterosexualidad. El niño es un niño imaginario, ese niño en Distancia de rescate es otro, se vuelve monstruoso. Porque lo que choca es el niño como imaginario de la futuridad y el real, con deseos y placeres propios, la maternidad como ideal opresor frente a la experiencia real. Distancia de rescate es un relato que se interrumpe por una voz, que no sabemos de dónde proviene, que se nos dice que es la del niño-monstruo, la de David, pero que parece más bien una voz adulta, la voz de la ley, de la norma. Con Edelman podríamos decir que el deseo lésbico aquí «encarna esta pulsión de muerte, esta jouissance intransigente, al figurar una implicación de la sexualidad en los empujes sin sentido de esta pulsión», fundamentalmente por su resistencia al significado unívoco de lo

2 La «interruqción», para flores, se puede pensar como la inserción de «un corte en una conversación, un modelo, un acto, un movimiento, una quietud, un tiempo» y la apertura de «la posibilidad a otros devenires u acontecimientos, a otras líneas de pensamiento. Desbarata el orden lineal del discurso, alterando la inmovilidad y pasmosa inercia de lo que se da por obvio» (flores, 2013: 22). 
real, pero también por «su rechazo de la espiritualización del futurismo reproductivo por medio del matrimonio» (2014: 51).

«Conservas» pone en escena, a su vez, una interrupción — la del embarazo- que se convierte en una inversión y una pausa. Teresita es, como la figura de «El Niño» en Edelman, pura futuridad porque es puramente imaginaria, representa el ideal de la mujer realizada como madre, de la procreación y de la familia nuclear. Tiene padres y abuelos, pero no existe más que en estado de pre-feto, de cuasi-feto, de almendra, de monstruo, de lo que va a ser, de lo que todavía no es, pero en algún momento será, porque la repetición de la familia heteronormativa es inevitable. La negación de la maternidad/paternidad, de la procreación, interrumpiría la reproducción de la heterosexualidad y de la «familia feliz» como futurización de vidas ideales. Se trata de una lógica normalizadora que vuelve inteligible al mundo con la imagen de la mujer-madre y del niño que hay que futurizar. Es por eso que, en ambos relatos, lo fantástico opera como interrupción del orden de lo real, en palabras de Jackson, una subversión de «los supuestos filosóficos dominantes que entienden la "realidad como una entidad coherente y simplista"» (1986: 45). Mientras en «Conservas» ese corte funciona solo como suspensión momentánea de los roles asignados y del orden previsible del mundo, en Distancia de rescate la interrupción es un breve, pero determinante, salto al vacío de la norma, donde se descubren el deseo y el amor sexo-disidentes.

\section{BiBLIOGRAFíA}

Ahmed, Sara (2019): La promesa de la felicidad. Una crítica cultural al imperativo de la alegría, trad. Hugo Salas, Caja Negra, Ciudad Autónoma de Buenos Aires.

Astorino Julieta, Lucas SAPOrosi \& Eugenia Zicavo (2017): «Un análisis sociocultural sobre la maternidad y el aborto en la literatura argentina reciente», Perífrasis, vol. 8, núm. 15 , pp. 44-57.

De LeONE, Lucía (2018): «Imaginaciones territoriales, cuerpo y género. Dos escenas en la literatura argentina actual», Estudios filológicos, núm. 62, pp. 31-43.

Deleuze, Gilles (1991): «Posdata sobre las sociedades de control», trad. Martín Caparós, en Christian Ferrer (ed.), El lenguaje literario, II, Nordan, Montevideo.

Despentes, Virginie (2007): Teoría King Kong, trad. Paul Preciado, Melusina, Madrid.

Domínguez, Nora (2007): De dónde vienen los niños. Maternidad y escritura en la cultura argentina, Beatriz Viterbo, Rosario.

DruCAROFF, Elsa (2018): «La cicatriz de lo que no se pronuncia (Apuntes sobre Distancia de rescate, de Samanta Schweblin)», en Actas de las XXX Jornadas de Investigación 
del Instituto de Literatura Hispanoamericana (marzo de 2018), Universidad de Buenos Aires, Buenos Aires, disponible en <http:/ /ilh.institutos.filo.uba.ar/sites / ilh.institutos.filo.uba.ar/files / Drucaroff\%2C\%20Elsa_2.pdf $>$ [27-07-2020]

Edelman, Lee (2014): No al futuro. La teoría queer y la pulsión de muerte, trad. Javier Sáez \& Adriana Baschuk, Egales, Barcelona.

FLORES, valeria (2013): Interruqciones. Ensayos de poética activista. Escritura, política, educación, La Mondonga Dark, Neuquén.

FortTES, Catalina Alejandra (2018): «El horror de perder la vida nueva: gótico, maternidad y transgénicos en Distancia de rescate de Samantha Schweblin», Revell. Revista de Estudios Literários de UEMS, vol. 3, núm. 20, pp. 147-162.

GonZÁlez DinamarCa, Rodrigo Ignacio (2015): «Los niños monstruosos en El Orfanato de Juan Antonio Bayona y Distancia de rescate de Samanta Schweblin», Brumal. Revista de Investigación sobre lo Fantástico, vol. III, núm. 2, pp. 89-106.

Halberstam, Jack (2018): El Arte queer del fracaso, trad. Javier Sáez, Egales, Barcelona.

JACKSON, Rosemary (1986): Fantasy. Literatura y subversión, trad. Cecilia Absatz, Catálogos, Buenos Aires.

Loria Araujo, David (2017): «Gestaciones abyectas: lecturas de la infancia y la maternidad en Guadalupe Dueñas y Samanta Schweblin», en Margaret Shrimpton Masson, David Loría Araujo \& Celia Rosado Avilés (eds.), Cuerpos abyectos: infancia, género y violencia, Universidad Autónoma de Yucatán, Mérida, pp. 247261.

Ortega Caicedo, Alicia (2017): «Escritura de mujeres: daño ambiental, orden materno, cartografías de la violencia», Revista Pucara, núm. 28, pp. 159-179.

PARIS, Diana (2014): «Samanta Schweblin. El "cuento" de la maternidad: de las hadas al terror», Ómnibus. Revista intercultural, núm. 48, pp. 15-27.

REYES CORTÉS, Rossana Jimena (2018): «Cuerpos monstruosos y escrituras abyectas, una revisión de la narrativa de Mariana Enríquez y Samanta Schweblin», Facultad de Filosofía y Humanidades, Universidad de Chile. Tesis de grado.

RosenberG, Martha (2007): «Maternidad. Perspectivas», en Susana Gamba \& Tania Diz (eds.), Diccionario de estudios de género y feminismos, Biblos, Buenos Aires, pp. 210-213.

Schweblin, Samanta (2012): Pájaros en la boca, Emecé, Buenos Aires.

- (2014): Distancia de rescate, Random House, Buenos Aires.

Silvestri, Leonor (2017): Enemiga pública. Interrogatorios y disparos, Del Signo, Ciudad Autónoma de Buenos Aires.

Todorov, Tzvetan (2011): Introducción a la literatura fantástica, trad. Elvio Gandolfo, Paidós, Buenos Aires.

Trejo Valencia, Gabriela (2018): “"Conservas” y Distancia de rescate: la narrativa fantástica de Samanta Schweblin a la luz de la (no) maternidad», Tenso Diagonal, núm. 6, pp. 84-92.

Williams, Raymond (2000): Marxismo y literatura, trad. Pablo di Masso, Península, Barcelona. 